\title{
Noncanonical Biogenesis of Centrioles and Basal Bodies
}

\author{
Catarina Nabais, Sónia Gomes Pereira, and Mónica Bettencourt-Dias \\ Cell Cycle Regulation Lab, Instituto Gulbenkian de Ciência (IGC), 2780-156 Oeiras, Portugal \\ Correspondence: cnabais@igc.gulbenkian.pt; sgpereira@igc.gulbenkian.pt; mdias@igc.gulbenkian.pt
}

\begin{abstract}
Centrioles and basal bodies (CBBs) organize centrosomes and cilia within eukaryotic cells. These organelles are composed of microtubules and hundreds of proteins performing multiple functions such as signaling, cytoskeleton remodeling, and cell motility. The CBB is present in all branches of the eukaryotic tree of life and, despite its ultrastructural and protein conservation, there is diversity in its function, occurrence (i.e., presence/absence), and modes of biogenesis across species. In this review, we provide an overview of the multiple pathways through which CBBs are formed in nature, with a special focus on the less studied, noncanonical ways. Despite the differences among each mechanism herein presented, we highlighted some of their common principles. These principles, governing different steps of biogenesis, ensure that CBBs may perform a multitude of functions in a huge diversity of organisms but yet retained their robustness in structure throughout evolution.
\end{abstract}

Centrioles and basal bodies (CBBs) are microtubulebased structures that assemble centrosomes and cilia. The centrosome is the dominant microtubule organizing center (MTOC) in most animal cells, thereby regulating intracellular transport, spindle pole formation, and establishing cellular polarity and migration. Each centrosome is composed of two cylindrical centrioles, often ninefold symmetric, surrounded by dynamic pericentriolar material (PCM). The PCM is responsible for anchoring and nucleating microtubules. Centrioles, then called basal bodies, can also anchor to the cell membrane and template the growth of motile and immotile cilia. In animals, most cell types form only one cilium (the primary cilium), but others can form hundreds (multiciliogenesis). These organelles are required for both cell and flow motility and sensing environmental cues.

It is essential that a cell regulates CBBs biogenesis to ensure they assemble at the right place, time, and number. Failure to regulate this process can lead to cellular defects and diseases. If cells possess more than two centrosomes at mitotic onset, they may assemble multipolar spindles and segregate the genome unevenly. This leads to aneuploidy, genomic instability, and cancer (Peel et al. 2007; Ganem et al. 2009; Silkworth et al. 2009; Godinho and Pellman 2014; Levine et al. 2017). Similarly, problems in cilia assembly cause a plethora of ciliopathies (Badano et al. 2006), which, in some cases, may arise from structural defects in the basal bodies (e.g., some mutations causing Bardet-Biedl syndrome [Ansley et al. 2003]).

CBBs are well-conserved structures present across the eukaryotic tree of life and probably derived from a basal body-like organelle already present in the last eukaryotic ancestor (LECA) (Cavalier-Smith 2002; Hodges et al. 2010). They have been lost within plant, fungi, and amoebae lineages or reduced to particular tissues or life-cycle stages in other groups, acquiring new morphologies and modes of biogenesis.
CBBs can assemble by several pathways; the best-characterized one is centriole duplication (Loncarek and Bettencourt-Dias 2018). This, hereafter called canonical pathway, occurs through the formation of two daughter centrioles close to two preexisting ones. In mitosis, one centrosome is segregated to each daughter cell, ensuring that cells maintain a correct centriole number when they proliferate. Canonical biogenesis is always coupled to the cell cycle, ensuring that CBBs only form once. Centrioles can also assemble through noncaninocal pathways, but less is know in terms of their regulation and origin, though they are widespread in nature.

In this review, we describe the diverse pathways through which CBBs are formed. We focus mostly on the noncanonical strategies, which have been less explored in the literature. We differentiate these strategies into two categories: deuterosome-mediated biogenesis, when centrioles form in bulk in the presence of preexisting centrioles, and de novo, strictly referring to biogenesis without any previously existing centrioles in the cell/organism. We highlight the similarities and differences between these pathways and discuss both their evolution and underlying molecular and cellular mechanisms.

\section{PATHWAYS OF BIOGENESIS}

\section{The Canonical Pathway (Centriole Duplication)}

In cycling cells, centrioles assemble in $\mathrm{G}_{1}$ to $\mathrm{S}$ transition, forming one daughter centriole orthogonally to each mother. The daughter centrioles elongate and, in late $G_{2}$, undergo centriole-to-centrosome conversion losing the cartwheel (in vertebrate cells) and recruiting PCM (Fu et al. 2016). Then, the two centrosomes migrate toward opposite poles of the cell organizing the mitotic spindle. After mitosis, each daughter cell inherits exactly one pair of centrioles (Fig. 1). 


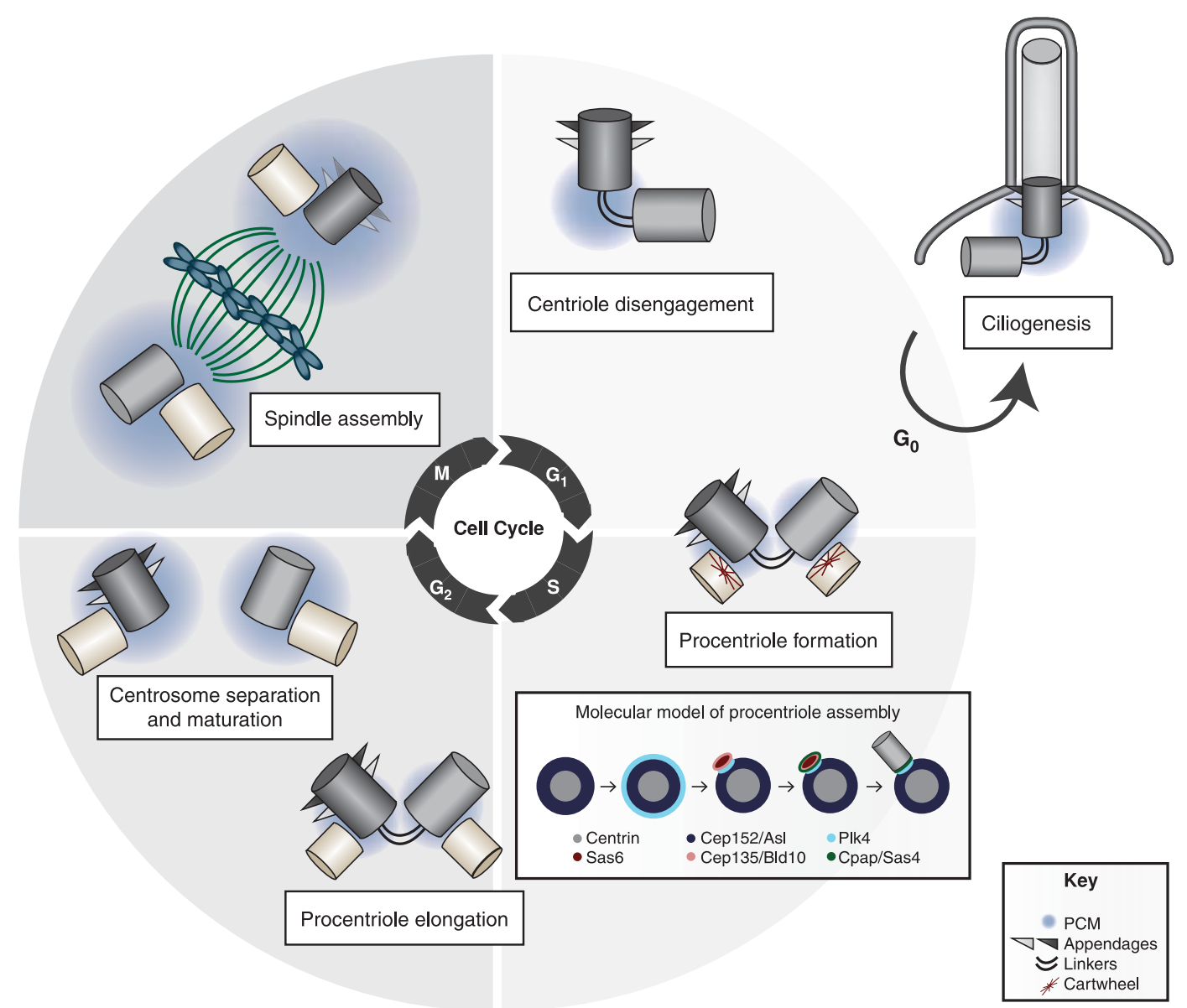

Figure 1. Canonical biogenesis in cycling cells. In early $\mathrm{G}_{1}$, cells have one centrosome with two centrioles (mother and daughter) orthogonally oriented. Before duplication, the two centrioles disengage $\left(\mathrm{G}_{1}\right)$, losing their orthogonal configuration, and both become mother centrioles (Robbins et al. 1968). From $\mathrm{G}_{1}$ to $\mathrm{S}$ transition, one procentriole forms orthogonally to each mother. The procentrioles elongate during the $\mathrm{G}_{2}$ phase and each centrosome starts recruiting PCM components (Robbins et al. 1968; Kuriyama and Borisy 1981). From $\mathrm{G}_{2}$ to mitosis, the two centrosomes separate and migrate toward opposite poles of the cell. Mitotic centrosomes recruit more PCM allowing them to organize the mitotic spindle. Upon mitotic completion, each daughter inherits exactly one pair of centrioles. At the beginning of each $\mathrm{G}_{1}$ phase, the oldest centriole acquires both distal and subdistal appendages (Kong et al. 2014). Procentriole assembly relies on the stepwise incorporation of conserved molecules (depicted in the inset). Cep152/Asl recruits Plk4, which phosphorylates downstream substrates, allowing the formation of the Sas6 and Cep135/Bld10 cartwheel, thus building the centriole core. Cep152/Asl also interacts with Cpap/Sas4, promoting the incorporation of PCM components (Cizmecioglu et al. 2010; Dzhindzhev et al. 2010; Gopalakrishnan et al. 2011; Sonnen et al. 2013).

Although we are not yet aware of all the details governing this process and preventing reduplication, the molecular pathways involved in triggering and coupling centriole duplication to the cell cycle have been extensively studied in recent years (Matsumoto et al. 1999; Meraldi et al. 1999; Harrison et al. 2011; Zitouni et al. 2016). Such mechanisms are not detailed here, but they have been covered by numerous reviews (Loncarek and Bettencourt-Dias 2018; Nigg and Holland 2018).

\section{Deuterosome-Mediated Biogenesis}

Postmitotic cells containing two resident centrioles can differentiate into multicilated cells (MCCs), assembling CBBs in large scale through the deuterosome-mediated pathway (Fig. 2; Meunier and Azimzadeh 2016). Many multiciliated vertebrate tissues - the respiratory tract, the oviduct, skin, efferent ducts, and the brain ependymalare composed of MCCs. These cells produce fluid flow and particle movement, through the coordinated beating of their motile cilia. We hereby describe multiciliogenesis in vertebrate MCCs, whose molecular aspects have been characterized in recent years, showing that deuterosomemediated and canonical biogenesis share part of their molecular cascade (Vladar and Stearns 2007; Azimzadeh et al. 2012; Klos Dehring et al. 2013; Zhao et al. 2013; Mori et al. 2017). We also speculate that a similar mechanism might contribute to the formation of multiciliated sperm in some invertebrates, such as in mollusks (Cipangopaludina malleata [Gall 1961] and Pyrazus ebeninus [Healy and Jamieson 1981]) and the insect Mastotermes darwiniensis (Baccetyi and Dallai 1978; Riparbelli et al. 2009).

In primary ciliogenesis, a single cilium derives directly from a CBB formed canonically, whereas in multicilio- 


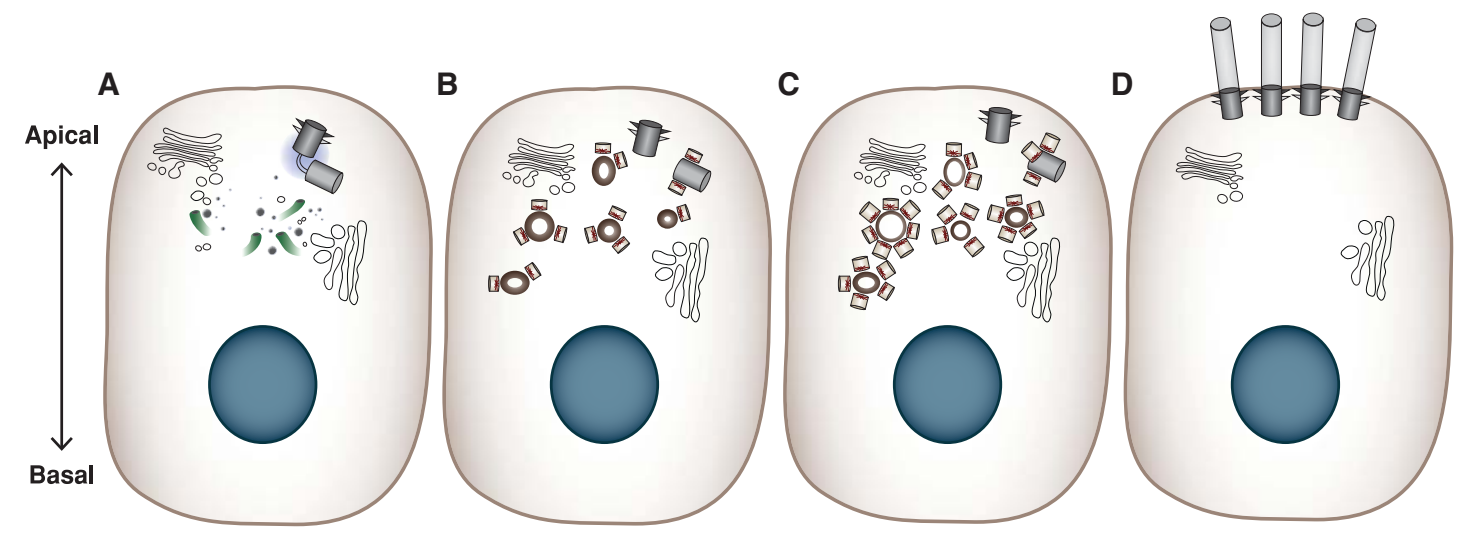

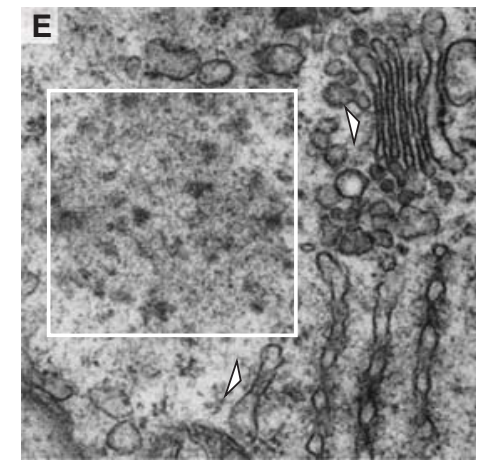

Rat - Lung epithelia (Sorokin 1968)

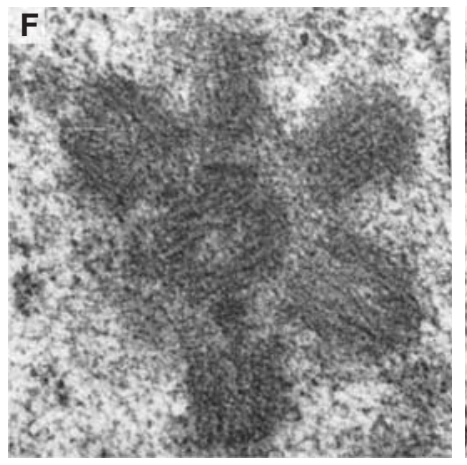

Rat - Lung epithelia (Sorokin 1968)

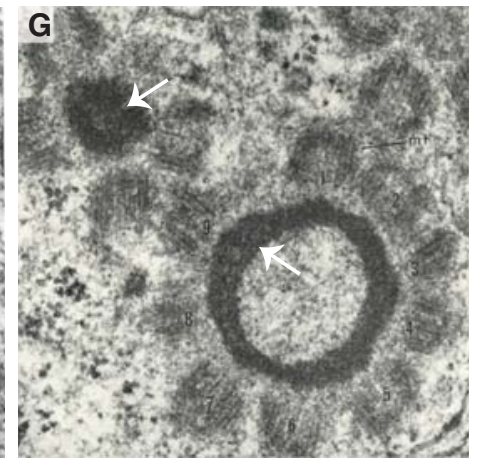

Mouse - Oviduct epithelia (Dirksen 1971)

\begin{tabular}{|c|c|c|c|}
\hline Key & $\begin{array}{l}\text { Fibrogranular material } \\
\text { ofo Golgi and Vesicles }\end{array}$ & $\begin{array}{l}\text { Microtubules } \\
\text { DNA }\end{array}$ & $\begin{array}{l}\text { - Deuterosome } \\
\text { Centrosome }\end{array}$ \\
\hline
\end{tabular}

Figure 2. Deuterosome-mediated biogenesis in vertebrate multicilated cells (MCCs). Multiciliogenesis starts with the formation of electron-dense "fibrogranular material" (in $A$ and depicted within the white square in the EM micrograph, $E$ ) in the cytosol, close to preexisting centrioles. This dense material is usually enriched with microtubules (MTs), Golgi cisternae, and vesicles ( $A, E$, arrowheads). The "fibrogranular material" condenses and deuterosomes - electron-dense hollow spheres - are formed ( $B, G$, arrows). A recent study in ependymal cells demonstrated that the resident daughter centriole is capable of generating multiple deuterosomes, which detach from its wall and give rise to many procentrioles $(B, C, G)$ (Al Jord et al. 2014). Additionally, procentrioles assemble directly around the resident centrioles $(C)$, as shown in the EM micrograph $(F)$. Hundreds of CBBs are formed in the cytosol, which then migrate and dock to the cell membrane assembling hundreds of cilia $(D) .(E[\times 37,000]$ and $F[\times 50,000]$ : Adapted, with permission, from Sorokin 1968 , Journal of Cell Science, 3: 207-230; G [×96,000]: adapted, with permission, from Dirksen 1971, Journal of Cell Biology, J51(1): 286302 DOI: $10.1083 / \mathrm{jcb} .51 .1 .286$.)

genesis, hundreds of basal bodies are generated, which nucleate hundreds of cilia. Centriole biogenesis in MCCs does not rely only on the association with preexisting centrioles but instead depends on additional specialized structures (deuterosomes) to efficiently assemble a large number of CBBs. Electron microscopy (EM) studies described the formation of electron-dense granules ("fibrogranular material") in the cytosol-usually in the vicinity of resident centrioles, in the apical region of the cell-as the first morphological evidence of ciliogenesis (Fig. 2A,E; Sorokin 1968; Steinman 1968; Kalnins and Porter 1969; Dirksen 1971; Hagiwara et al. 2004; Vladar and Stearns 2007). Progressively, these granules increase in size and condense into large spherical bodies, the deuterosomes, which show no discernible structure but are extremely electron-dense (Fig. 2B,C,G); suggesting they consist of concentrated proteins. Frequently, numerous
Golgi cisternae, small vesicles, and microtubules were seen in the vicinity of deuterosomes (Fig. 2A,E; Sorokin 1968; Kalnins and Porter 1969; Dirksen 1971; Vladar and Stearns 2007), suggesting these organelles might contribute to deuterosome formation and procentriole biogenesis. Although Golgi and vesicles, together with microtubule activity, can supply the deuterosome with precursors, preexisting centrioles might contribute with activating enzymes catalyzing biogenesis from the centriolar precursors. One such case, can be mediated by the activity of the Polo-like kinase 4 (Plk4), a master regulator and upstream player in centriole assembly (Bettencourt-Dias et al. 2005; Habedanck et al. 2005).

Several evenly spaced procentrioles assemble simultaneously from each deuterosome (Fig. 2B,C,G). In most tissues, procentrioles form both around the amorphous deuterosome (acentriolar-mediated) (Fig. 2G) and the pre- 
existing centrioles (centriolar-mediated) (Fig. 2F; Sorokin 1968; Anderson and Brenner 1971; Hagiwara et al. 2004; Al Jord et al. 2014). During ependymal MCC differentiation, deuterosomes arise from the wall of the (preexisting) daughter centriole (Al Jord et al. 2014). Nonetheless, in all tissues, most of the centrioles $(70 \%-90 \%)$ are generated via deuterosomes rather than directly from centrosomal centrioles. The specific centriole amplification mechanism used by different MCCs might then depend on the number of cilia they produce (Meunier and Azimzadeh 2016). Procentrioles separate from the clusters, mature, and become typical basal bodies nucleating motile cilia.

Only recently, the molecular mechanisms driving deuterosome formation started to be understood. The multiciliogenesis program starts with down-regulation of the Notch signaling pathway in MCCs precursors. Then, MCCs activate a cascade, mediated by the GemC1-Multicilin-E2f4/5 complex, triggering cell cycle exit, cytoskeleton remodeling, and up-regulation of several centriole biogenesis components, including Cep152/Asl, Plk4, Cpap/Sas4, Sas6, Stil/Sas5, and centrin (Vladar and Stearns 2007; Hoh et al. 2012; Zhao et al. 2013; Mori et al. 2017; Arbi et al. 2017). These proteins are usually at very low abundance in cycling cells, hence limiting the number of centrioles that are formed. MCCs also express deuterosome-specific components, Deup1 (a paralog of Cep63) and Ccdc78, which localize to the center of the deuterosome (Klos Dehring et al. 2013; Zhao et al. 2013). Deup1 binds Cep152/Asl, which then recruits Plk4, kickstarting the centriole biogenesis molecular cascade (Zhao et al. 2013; Al Jord et al. 2014; Mori et al. 2017). As MCCs start differentiating, E2f4 moves from the nucleus to the cytosol, where it interacts with Deup1 (Mori et al. 2017). Cep152/Asl, Plk4, and centrin are subsequently enriched at the deuterosome and at the preexisting centrioles, seeding the biogenesis of multiple CBBs. E2f4 has a dual role in the cell; first driving the transcription of centrosomal components and later participating in their assembly in the cytoplasm.

Nevertheless, it is still left to determine how centriole amplification stops. Is there a feedback mechanism that terminates centriole amplification? Or does it simply result from exhaustion of centrosomal components?

\section{De Novo}

Centrioles can assemble de novo (i.e., without centriolar structures present in the cell) in several species. However, in most naturally occurring cases (see Fig. 6; Supplemental Table S1), the mechanisms remain poorly understood. Centrioles may arise as single units (Fig. 3), as two centrioles coaxially oriented (bicentriole; Fig. 4), or in electron-dense spheres (blepharoplasts; Fig. 5) in which the number of CBBs assembled varies (Miki-Noumura 1977; Riparbelli et al. 1998; Renzaglia and Garbary 2001). Amoebae to flagellate transition in Naegleria gruberi is accompanied by the biogenesis of two centrioles. Because amoebae lack centrioles and microtubules, and so far no basal body precursor has been found, it was proposed that centrioles assemble de novo (Dingle and Fulton 1966; Fulton and Dingle 1971). By studying the localization of centrin and $\gamma$-tubulin during this transition, Fritz-Laylin et al. (2016) have shown that only the first centriole assembles de novo, whereas the second one appears to duplicate from the first. There is no EM support for the underlying pathway and, despite some molecular insights from recent studies (Suh et al. 2002; Kim et al. 2005; Fritz-Laylin et al. 2010; Lee et al. 2015; Fritz-Laylin and Fulton 2016), the exact molecular cascade is still unknown.

Other examples of de novo biogenesis of single centrioles take place in parthenogenetic insect eggs (in Muscidifurax uniraptor [Fig. 3; Riparbelli et al. 1998], and Drosophila mercatorum [Riparbelli and Callaini 2003]) and artificially activated eggs of sea urchin (Dirksen 1961; Miki-Noumura 1977) and in the surf clam Spisula solidissima (Fig. 6; Supplemental Table S1; Kuriyama et al. 1986; Palazzo et al. 1992). As in most animals, centrioles are lost during oogenesis (Fig. 3A) and are delivered to the egg by the sperm upon fertilization. In activated hemynopteran eggs, multiple microtubule asters containing single centrioles are formed along the cortex
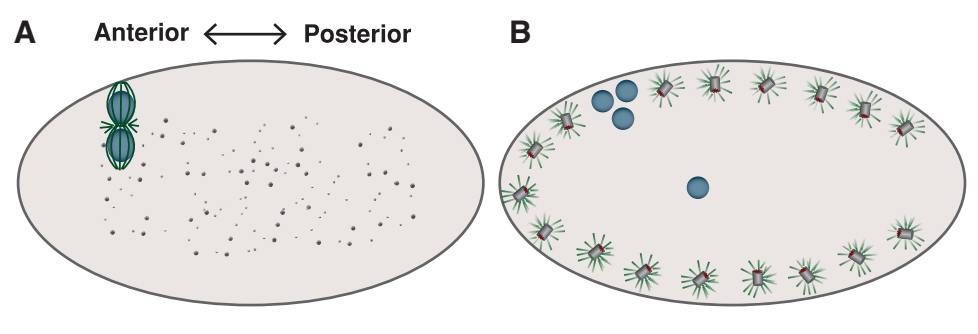

C

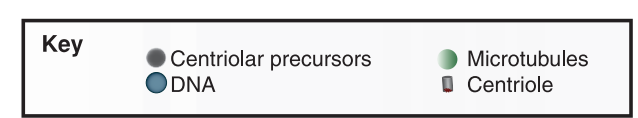

Figure 3. De novo centriole biogenesis in parthenogenic insect eggs. Unfertilized eggs do not have centrioles but contain high levels of centriolar precursors $(A)$. Upon egg activation and meiotic resumption, centrioles are formed de novo along the cell cortex $(B)$. These single centrioles nucleate MT asters. Meiosis is completed and the free centrosomes migrate toward the egg center $(C)$. Two asters interact with the female pronucleus, assembling the first mitotic division and triggering embryonic development ( $C$, black rectangle). The remaining centrosomes degenerate (Riparbelli et al. 1998). 
A

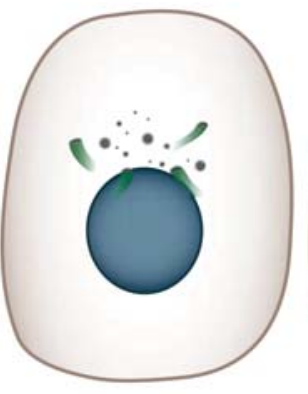

B

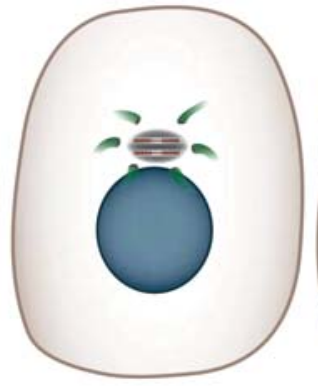

C

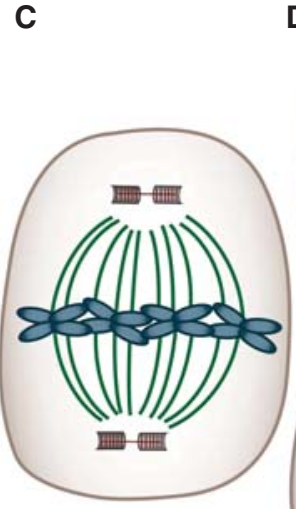

D

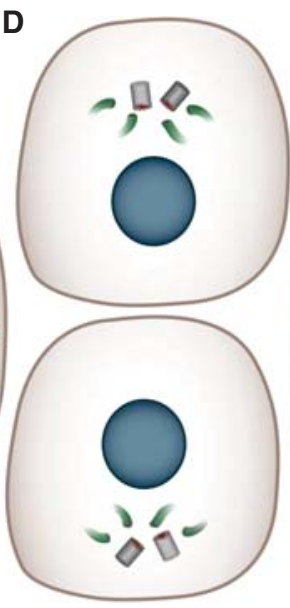

E

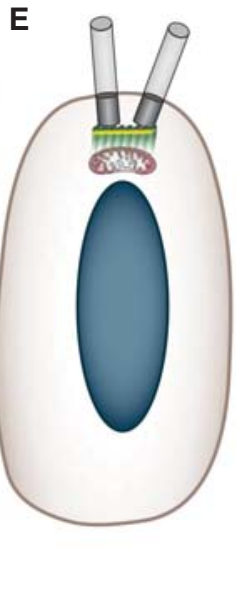

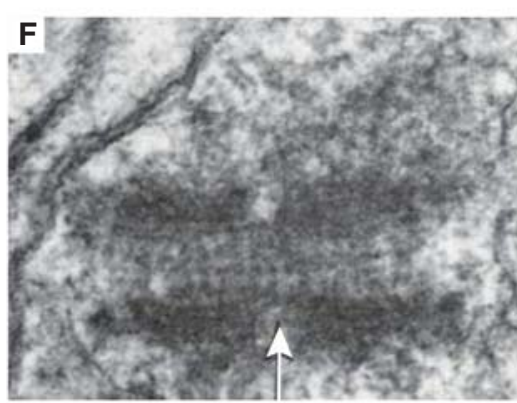

Liverwort (M. polymorpha) - Spermatid (Moser and Kreitner 1970)

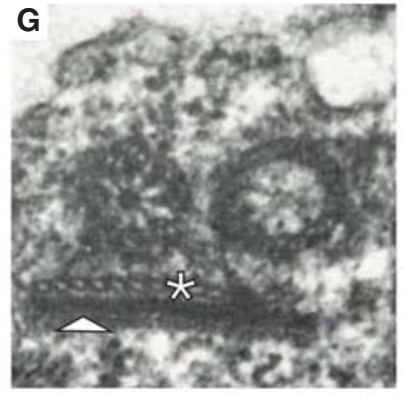

Liverwort (M. polymorpha) - Spermatid (Moser and Kreitner 1970)

$$
\begin{array}{|lll}
\text { Key } & \text { Microtubules } & \text { Mitochondria } \\
\text { DNA } & \text { Centriole }
\end{array}
$$

Figure 4. Bicentriole-mediated biogenesis in land plants with biciliated sperm. During spermatogenesis, electron-dense material enriched in microtubules (MTs) is found near the nuclear envelope $(A)$. This material assembles into two light lobes, surrounded by a darker matrix $(B)$. As mitosis begins, the two lobes separate, migrate toward the spindle poles and mature into bicentrioles $(C)$. Bicentrioles are composed of two coaxial centrioles connected by their central hub and with discontinuous MT triplets $(F$, white arrow). Each daughter cell (spermatid) inherits one bicentriole that breaks in half and separates into two centrioles $(D)$ that will migrate to the edge of the cell and anchor to the multilayered structure (MLS), serving as basal bodies during ciliogenesis (E, $G$ ). The MLS is composed of a bundle of parallel MTs - the spline $(G$, asterisk) - and layers of electron-dense material - the lamellar strip $(G$, arrowhead). $(F[\times 50,000]$ and $G[\times 50,000]$ : Adapted, with permission, from Moser and Kreitner 1970, Journal of Cell Biology, 44(2): 454-458 DOI: $10.1083 /$ jcb.44.2.454.)

(Fig. 3B). These migrate toward the center of egg. Parthenogenetic development is initiated when two asters are captured by the female pronuclei forming the first mitotic spindle (Fig. 3C; Riparbelli et al. 1998; Tram and Sullivan 2000).

The centriole in the mouse sperm is unable to nucleate microtubules after fertilization (Schatten et al. 1985; Gueth-Hallonet et al. 1993), so the first embryonic divisions are acentrosomal (Gueth-Hallonet et al. 1993; Courtois et al. 2012) and centrioles are only detected by EM from 64-cell stage onward (Gueth-Hallonet et al. 1993). Throughout the first mitotic divisions, the spindles become progressively more focused and are enriched with PCM and centriolar components, such as centrin, pericentrin, and CP110. Nevertheless, the trigger underlying centriole assembly is still unclear. A gradual concentration of PCM and centriolar components throughout the mitotic cycles could allow crossing a molecular threshold that finally enables the formation of centrioles (Courtois et al. 2012).

Oocytes represent a very particular cell type that is loaded with centriolar components; therefore, mechanisms blocking spontaneous centriole assembly could be present. Although in most eggs, centrioles do not assemble spontaneously, overexpression of Plk4 is enough to drive de novo formation of multiple centrioles (Peel et al. 2007; Rodrigues-Martins et al. 2007).

In most cases, centrioles assembled de novo seem to be able to replicate through the canonical pathway (Palazzo et al. 1992; Rodrigues-Martins et al. 2007; Fritz-Laylin et al. 2016). Therefore, in cases where several centrioles are observed, we cannot exclude that some could result from duplication following de novo biogenesis. Moreover, in Naegleria, both CBBs form cilia, indicating that centrioles formed de novo and canonically are equally capable of nucleating cilia without the need of a full cell cycle to mature. 
A

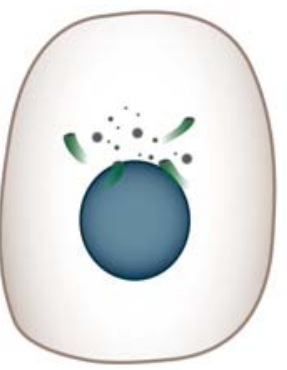

B

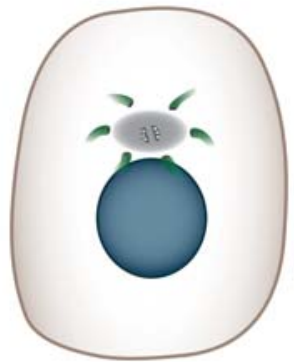

C

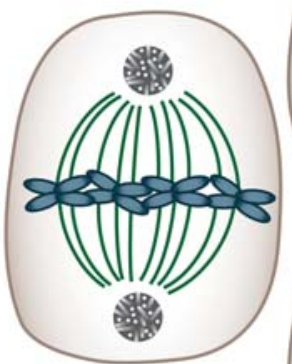

D

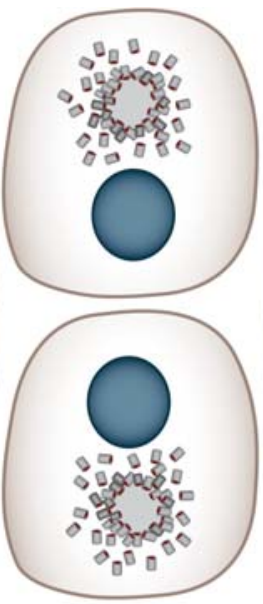

$\mathrm{E}$

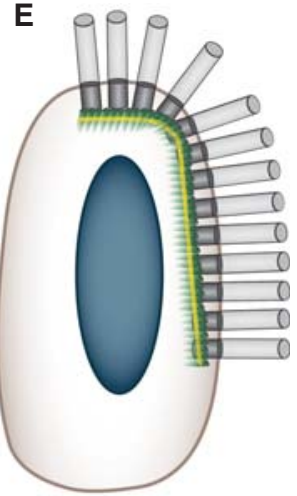

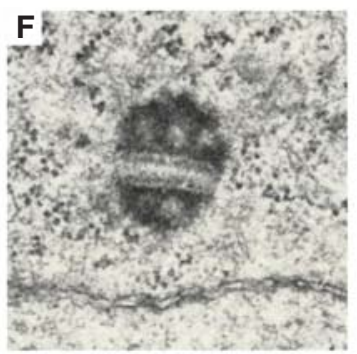

Fern (M. vestita) - Spermatid (Hepler 1976)

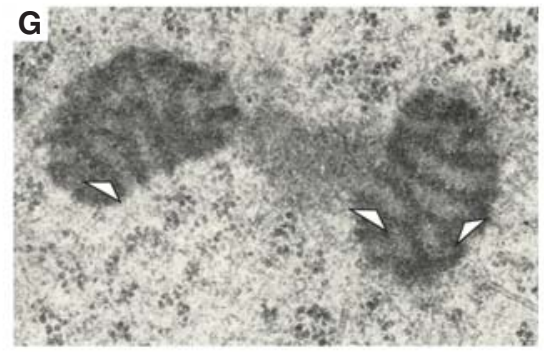

Fern (M. vestita) - Spermatid (Hepler 1976)

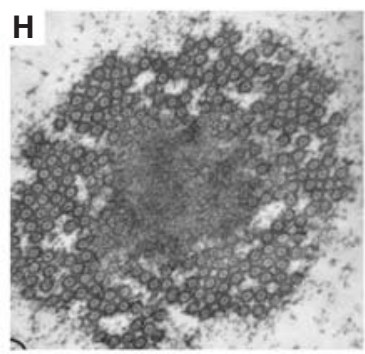

Cyca (Z. pumila) - Spermatid (Mizukami and Gall 1966)

\begin{tabular}{|c|c|c|c|}
\hline Key & $\begin{array}{l}\text { Centriolar precursors } \\
\text { DNA }\end{array}$ & $\begin{array}{l}\text { Microtubules } \\
\text { C Centriole }\end{array}$ & $\begin{array}{l}\text { Bi: Blepharoplast } \\
\text { MLS }\end{array}$ \\
\hline
\end{tabular}

Figure 5. Blepharoplast-mediated biogenesis in land plants with multiciliated sperm. In plants with multiciliated sperm, an electrondense agglomerate of material and microtubules (MTs) is first detected near the nuclear envelope of the sperm mother cell $(A)$. This material develops into two darker hemispherical lobes, intercalated by lighter cylinders $(B, F, G$, arrowheads). As the cell approaches mitosis, the lobes enlarge and separate $(G)$. Each lobe migrates to a pole of the mitotic spindle and assembles a blepharoplast $(C)$. Each spermatid inherits one blepharoplast, where many centrioles are assembled. The blepharoplast eventually collapses releasing the individual centrioles $(D, H)$ that will migrate and anchor to the MLS, giving rise to the basal bodies of the several cilia $(E)$. $(F[\times 37,000]$ and $G[\times 37,000]$ : Adapted, with permission, from Hepler 1976, Journal of Cell Science, 21: 361-390; H [×21,000]: adapted, with permission, from Mizukami and Gall 1966, Journal of Cell Biology, 29(1): 97-111 DOI: 10.1083/jcb.29.1.97.)

Bicentriole. De novo centriole biogenesis through bicentrioles is known to occur in plants with biflagellated sperm, such as bryophytes, as well as in the protist Labyrinthula spp. (Fig. 6; Supplemental Table S1; Perkins 1970). A bicentriole is composed of two centrioles oriented end-to-end, aligned along the same axis, and connected by a continuous cartwheel hub and discontinuous triplet microtubules (Fig. 4C,F; Moser and Kreitner 1970; Robbins 1984).

In land plants, two bicentrioles appear simultaneously in the sperm mother cell. First, an electron-dense body without any recognizable structure is detected in the outer surface of the nucleus. Microtubules emanate from this structure, suggesting that it has MTOC activity (Fig. 4A). Next, it separates into two different lobes (pro-bicentrioles) with a lighter stained central core surrounded by a darker matrix (Fig. 4B; Robbins 1984). Before mitosis, the two pro-bicentrioles separate, migrate toward the poles of the cell, and mature into bicentrioles, assembling MT triplets (Robbins 1984; Renzaglia and Duckett 1987). Each bicentriole at the spindle pole contains two coaxial centrioles (Fig. 4C,F; Moser and Kreitner 1970; Robbins 1984).

Each spermatid inherits one bicentriole. The central hub breaks at its midpoint and the two resulting centrioles undergo planar rotation becoming almost parallel to each other, with their proximal ends facing the same direction (Fig. 4D; Moser and Kreitner 1970; Kreitner and Carothers 1976; Robbins 1984). Centriole reorientation is accompanied by the development of the multilayered structure (MLS), immediately below the centrioles (Fig. 4E,G). The MLS is composed of a bundle of parallel microtubule singlets - the spline (Fig. 4G, asterisk) and by the lamellar strip (layers of electron-dense material) (Fig. 4G, arrowhead). The centrioles anchor to the MLS and become basal bodies for ciliogenesis (Fig. 4E; Moser et al. 1977; Renzaglia and Duckett 1987).

There is no available molecular data on centriole assembly through bicentrioles, except that these structures appear to contain $\gamma$-tubulin (Shimamura et al. 2004). The only study reporting the early stages of de novo bicentriole assembly is from Robbins (1984) on spermatogenesis in 


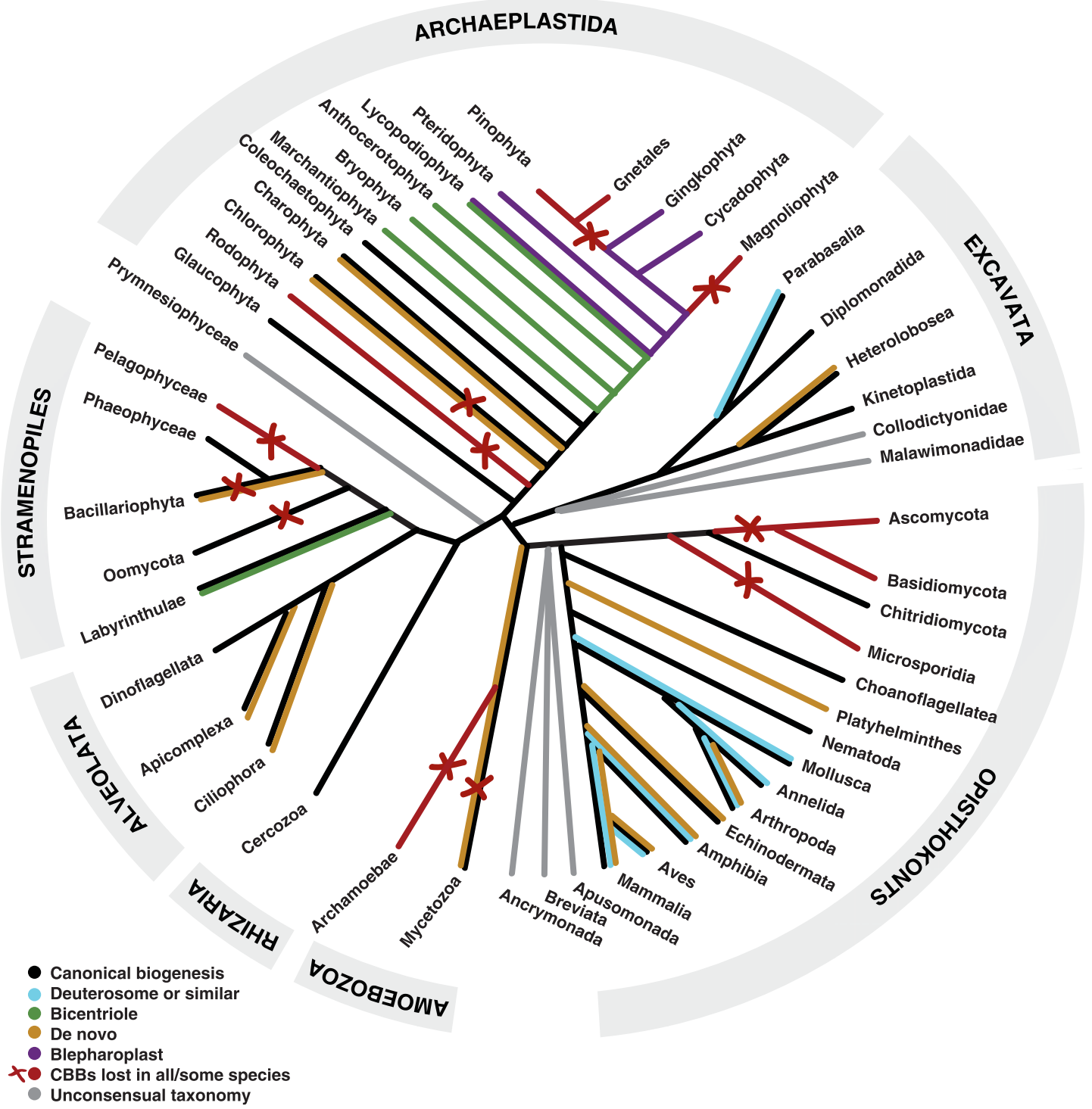

Figure 6. Consensus eukaryotic tree of life (selected groups; following Burki 2014 and Worden et al. 2015). The distinct centriole biogenesis pathways are represented in different colors. Canonical biogenesis (in black) is the most prevalent pathway and probably, the ancestral one. Deuterosomes (blue), the bicentriole (green), and blepharoplast (purple) are all evolutionary innovations, arising relatively recently in the eukaryotic history. Some pathways are more restricted to some groups - for example, the canonical and deuterosome pathways are predominant in vertebrates, whereas most plants assemble CBBs through a bicentriole or a blepharoplast. There are some striking exceptions, like the presence of a deuterosome-like mechanism in the sperm of some invertebrates. Whereas in gastropods (Mollusca) the noncanonical pathway seems to be centriolar, where up to $20 \mathrm{CBBs}$ assemble only around the existing centrioles, the sperm from annelids and Mastotermes darwiniensis (Arthropoda) possesses a very high number of CBBs, likely formed via both centriolar and acentriolar ways. Similarly, within the class Parabasalia (Excavata) some protists undergo massive centriole amplification. It is proposed that biogenesis is driven by resident centrioles along a "ladder"-like configuration (Tamm and Tamm 1980). In all these studies, no typical deuterosomes were detected, only occasional clouds of electron-dense material containing microtubules. There are other examples of convergent evolution among pathways, such as the presence of a bicentriole in Labyrinthulae (Stramenopila). Future studies should be expanded to more species in less known groups to clarify the mechanism involved in de novo biogenesis (orange) and understanding if they are all a result of lineage-specific evolution (convergent evolution). CBBs were lost in multiple lineages (red lines and crosses, absent in all species within the groups; red crosses, lost in only some species within the lineage).

the bryophyte Riella americana. Early land plants, such as Marchantia polymorpha, Physcomitrella patens, and Selaginella moellendorffii are model organisms that assemble CBBs through the bicentriole pathway and therefore, could be used to better describe this pathway and understand its regulatory mechanisms.
Blepharoplast. In land plants with multiciliated sperm such as ferns, cycads, and Ginkgo (Fig. 6; Supplemental Table S1), CBBs are formed through blepharoplasts. The blepharoplast arises de novo as a spherical electron-dense organelle that is initially amorphous (Fig. 5A), and during maturation it becomes intercalated by lighter cylinders 
embedded in an electron-opaque matrix. These cylinders mature into centrioles that later give rise to the basal bodies of multiple cilia (Fig. 5; Hepler 1976; Gifford and Larson 1980).

Blepharoplast biogenesis starts with the appearance of two hemispherical densely stained structures near the cell nucleus (Fig. 5B,F). Then, cylinders organize within the electron-dense matrix (Fig. 5G, arrowheads), with microtubules emanating from the blepharoplast. These structures grow and become spherical, giving rise to two blepharoplasts (Mizukami and Gall 1966; Hepler 1976; Hoffman and Vaughn 1995). The two blepharoplasts separate (Fig. 5G) and migrate to the spindle poles of the mitotic cell, where they appear to act as MTOC (Fig. 5C; Hepler 1976; Gifford and Larson 1980; Doonan et al. 1986). In the metaphase-anaphase transition of the last mitosis, the blepharoplast becomes more diffuse and loses its MT-nucleating ability. The cylinders acquire a ninefold symmetry and a hub-and-spokes configuration, therefore resembling procentrioles. Each daughter cell inherits one blepharoplast (Norstog 1967; Gifford and Lin 1975; Hepler 1976). Sperm development proceeds as centrioles are formed (Fig. 5D,H; Hepler 1976; Renzaglia and Maden 2000). The blepharoplast eventually collapses, resulting in individualized centrioles (Fig. $5 \mathrm{H}$ ). The centrioles dock into the MLS and function as basal bodies nucleating axonemes (Fig. 5E; Mizukami and Gall 1966; Doonan et al. 1986; Norstog 1986).

Molecular characterization of blepharoplast assembly is still scarce. However, a few studies have reported the localization of centrin, acetylated, tyrosinated, and $\beta$-tubulins at the blepharoplast (Doonan et al. 1986; Klink and Wolniak 2001; Vaughn and Renzaglia 2006). Centrin's function was studied in Marsilea vestita, in which RNAi experiments highlighted its requirement for proper blepharoplast and centriole biogenesis (Klink and Wolniak 2001).
To this date, there is no evidence for centriole duplication in multiciliated plant cells. It appears that each CBB formed de novo only gives rise to one cilium (Mizukami and Gall 1966; Norstog 1967, 1986; Gifford and Lin 1975).

\section{MECHANISMS UNDERLYING CBBS ASSEMBLY}

In spite of the diversity of pathways, their outcome is the same: the generation of CBBs with a conserved ultrastructure and function. The mechanism used by each cell type and organism to build it seems highly dependent on the number of CBBs they have to begin with and how many will be generated.

Regulation of centriole number is still not fully understood. In the canonical pathway number regulation is partially achieved by coupling of the centriole and cell cycles, but this cannot be the case in the noncanonical pathways. One possibility, is that centriole number only depends on the amount of its building blocks, and as centrioles are assembled, these are depleted. Under this hypothesis, number regulation would take place mostly at the levels of transcription and translation. Another strategy would be the activation of a negative feedback mechanism wherein, once the right amounts of centrioles are assembled, any further biogenesis is inhibited. Studies indicate that even noncanonical pathways show some centriole number regulation because each multicilated cell type assembles a consistent $\mathrm{CBB}$ number.

Nevertheless, canonical and noncanonical pathways share many striking similarities. Two centriolar proteinsSas6 and centrin - and pericentriolar components $\gamma$-tubulin and pericentrin have been shown to be present in both canonical and noncanonical pathways in multiple species (Fig. 7). Sas6 is the most conserved centriolar protein and

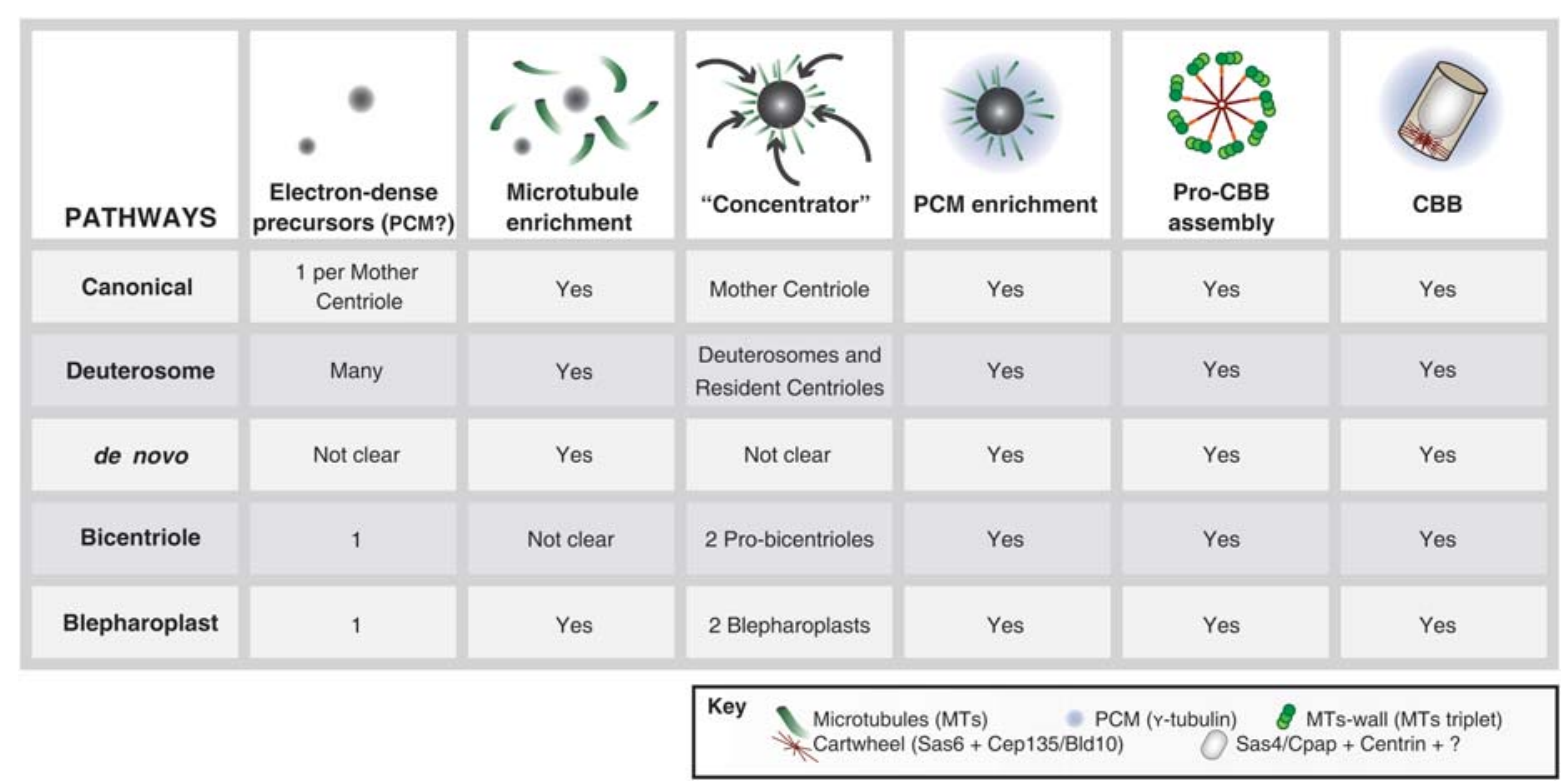

Figure 7. Common principles underlying centriole biogenesis among known pathways. 
the major molecular component of the cartwheel, forming ninefold symmetrical stacks at the core of the centriolar barrel (Nakazawa et al. 2007; van Breugel et al. 2011; Kitagawa et al. 2011). In plants, centrin and $\gamma$-tubulin are enriched in the blepharoplast of Ceratopteris richardii (Hoffman et al. 1994), and functional studies demonstrated that centrin is needed to form the blepharoplast and therefore the ciliary apparatus in $M$. vestita sperm (Klink and Wolniak 2001). De novo CBB formation in N. gruberi is preceded by the formation of a $\gamma$-tubulin, pericentrin, and myosin II complex, at the site where Sas6 and centrinpositive centrioles assemble (Fritz-Laylin et al. 2010; Lee et al. 2015; Fritz-Laylin and Fulton 2016). In vertebrates, all of these previously mentioned components along with others localize to centrioles generated de novo in mammalian culture cells (Khodjakov et al. 2002; La Terra et al. 2005; Uetake et al. 2007) and are up-regulated in multiciliogenesis (Vladar and Stearns 2007; Klos Dehring et al. 2013; Zhao et al. 2013; Mori et al. 2017). Though the molecules are the same, differential regulation of their levels allows overcoming the canonical biogenesis regulation and assembling multiple $\mathrm{CBBs}$.

The location where procentrioles assemble is determined by the site where its precursors concentrate, herein called "concentrator." Even though the "concentrator" might be morphologically distinct in each centriolar or acentriolar pathways, components must first accumulate in a defined location in the cytosol, and subsequently seed the growth of CBBs. In the canonical pathway the mother centriole acts as a concentrator, whereas in the noncanonical pathways organisms evolved multiple structures where centriolar components are specifically enrichedthe blepharoplast, the deuterosome, and other electrondense structures. This way, the concentrator regulates the location and number of CBBs assembled (Fig. 7).

The microtubule cytoskeleton helps transporting components to the concentrator (Fig. 7). CHO cells, upon centriolar removal and if treated with nocodazole, no longer form centrioles de novo (Khodjakov et al. 2002). Multiciliogenesis is accompanied by cytoskeleton remodeling that promotes assembly of stable cytoplasmic microtubules (more resistant to depolymerization) (Vladar and Stearns 2007). Microtubule enrichment is also detected close to the fibrogranular material preceding deuterosome formation (Steinman 1968; Dirksen 1971) and microtubules regrow from the blepharoplast after depolymerization (Vaughn and Bowling 2008). Overall, multiple observations hint that microtubules are important for CBBs assembly, however it is still left to determine when exactly they are critical. Are they needed in the very early stages of precursor concentration? Or do they only facilitate recruitment once there is already a centriolar primordium? Some components might have evolved affinity for the MTs, naturally concentrating at the MTOCs and facilitating the process. Among those components, PCM proteins are known to be required to stabilize centrioles and allow efficient centriole duplication (Dammermann et al. 2004; Pimenta-Marques et al. 2016). Proteins like chTOG/XMAP215, members of the Tacc family, Cpap/ Sas4, and $\gamma$-tubulin are important for PCM assembly and microtubule organization and are widely present in eukaryotes (Dammermann et al. 2004; Peset and Vernos 2008; Hodges et al. 2010). PCM might help concentrating centriolar proteins; therefore stable PCM aggregates in the cytosol might create a suitable environment for CBBs biogenesis (Fig. 7; Varmark et al. 2007; Dzhindzhev et al. 2010).

Finally, self-assembly and catalytic activity of centrosomal components are important in driving CBBs biogenesis. In several animals, Plk4 is the main kinase triggering centriole biogenesis. Plk4 controls its own activation by trans-autophosphorylation, which results in a positive feedback loop dependent on Plk4 concentration (Lopes et al. 2015). Self-assembling properties facilitate Sas6 oligomerization in vitro (Kitagawa et al. 2011). Together with Cep135/Bld10, these two Chlamydomonas proteins are able to assemble a cartwheel, the first step in building the centriolar core (Guichard et al. 2017). Recent studies have also shown that some centrosomal components spontaneously form condensates in vitro. Above a critical concentration, C. elegans Spd5 (a master PCM recruiter), forms a supramolecular scaffold where other PCM proteins can bind (Woodruff et al. 2017). Spd5 condensates enriched with chTOG and TPX2 are capable of concentrating $\alpha$ - and $\beta$-tubulin and organizing microtubule asters. Future work should dissect the role of self-assembling in vivo.

\section{EVOLUTIONARY HISTORY OF CBBs AND THEIR PATHWAYS}

Several lines of evidence support that CBBs are the same identity that was co-opted throughout evolution to perform different functions within the eukaryotic cell. Not only CBBs are ultrastructurally similar and co-occur across distinct "taxa," but the same gene network, the core centriolar assembly, is conserved in the genome of ciliated species (Woodland and Fry 2008; Carvalho-Santos et al. 2010; Hodges et al. 2010). Indeed, CBBs are found in all seven major eukaryotic lineages (Fig. 6; Supplemental Table S1), suggesting they were already present in the LECA but apparently not before (Carvalho-Santos et al. 2010). The ancestral CBB was most likely a basal bodylike organelle composed of nine microtubule triplets arranged in a radially symmetrical cylinder (Beisson and Wright 2003) involved in the nucleation of motile cilia (Carvalho-Santos et al. 2011; Azimzadeh 2014). CBBs (and their gene repertoire) have been independently lost in several lineages and are frequently absent in some plants (Archaeplastida), fungi (Opisthokonts), and amoebae (Amoebozoa) (Fig. 6; Renzaglia and Garbary 2001; Woodland and Fry 2008; Carvalho-Santos et al. 2011; Judelson et al. 2012; Yubuki and Leander 2013).

Throughout evolution, the requirement for ciliary motility imposed a functional constrain on basal body architecture, as absence of cilia allowed for complete centriole loss and the generation of MTOCs with very distinct morphology like the spindle pole body (SPB) of fungi and the nuclear-associated body (NAB) of amoebae 
(Supplemental Table S1; Hodges et al. 2010; Azimzadeh 2014)

Although cilia are seemingly ancestral structures, centrosomes most probably are not. A good example is the animal centrosome, which is mostly composed by Holozan-specific components (Holozoa is an Opisthokont subdivision including animals and closely related organisms except fungi) (Hodges et al. 2010). Recently, Gouw et al. (M Gouw, unpubl.) used maximum parsimony landscapes to assess the probability of the cilium and the centriolebased centrosome being ancestral in specific eukaryotic lineages. This analysis favored a convergent evolution hypothesis for the origin of centriole-based centrosomes, suggesting that centrioles were co-opted as part of the centrosomes independently in different eukaryotic lineages. The acquisition of centrosomal functions might have occurred in a stepwise manner. First, by becoming part of the spindle poles, CBBs could segregate equally to daughter cells upon cell division. This could favor an enrichment in PCM, potentiating MTOC activity. Finally, the acquisition of cell cycle components (Lange 2002) would link centrosome biogenesis and segregation to cell cycle progression, allowing a much tighter regulation of its activity and copy number in cells (Nigg and Holland 2018).

All pathways share components; a specific set of centriolar proteins-Sas6, Cpap/Sas4, Cep135/Bld10, Poc1, centrin - and $\alpha-, \beta-$, and $\gamma$-tubulin are found in the genome of most eukaryotic species that assemble CBBs (Fig. 7; Carvalho-Santos et al. 2010; Hodges et al. 2010). Functional studies and expression data are still scarce outside Opisthokonts, but are needed to validate the function of these components in each pathway.

Canonical duplication is the most prevalent pathway and probably, the ancestral one. It is present in every main branch of the eukaryotic tree, though the mechanism is somewhat different in specific taxa. In some oomycetes such as Saprolegnia ferax and Phytophthora infestans (Stramenopiles) and in Plasmodiophora spp. (Rhizaria) (Fig. 6; Supplemental Table S1), daughter centrioles assemble in a $180^{\circ}$ angle from their mother (coaxial orientation), rather than the usual $90^{\circ}$, forming a bicentriole, similar to the one found in some plants (Heath and Greenwood 1970; Heath 1974a,b; Garber and Aist 1979).

Not only the centriole-based centrosomes, but also deuterosomes, bicentrioles, and blepharoplasts are all evolutionary innovations, arising relatively recently in eukaryotic history (Fig. 6). A recent study argued that the deuterosome-mediated pathway is vertebrate-specific, arising just before tetrapode divergence. That is based on evidence that Deup 1, a specific component of the deuterosome resulting from Cep63 duplication, is only found in the genomes of lobe-finned fish and tetrapods (Zhao et al. 2013). Some gastropodes (C. malleatus and P. ebeninus), annellides (Tubifex spp.), and the termite Mastotermes darwiniensis produce multiciliated sperm (Fig. 6; Supplemental Table S1; Gall 1961; Baccetyi and Dallai 1978; Healy and Jamieson 1981; Ferraguti et al. 2002; Riparbelli et al. 2009). In these naturally occurring cases, the sperm basal bodies might derive from a mechanism similar to the deuterosome. In all these studies, no typical deuterosomes were detected, only occasional clouds of electron-dense material containing microtubules.

Archaeplastida, the group including plants and some algae, suffered multiple events of centriole loss, both in basal groups (in some green algae and in red algae altogether) and in gymnosperms after the split of conifers and gnetales from cycads and ginkgophytes and once again before angiosperm evolution (Magnoliophyta) (Bremer et al. 1987; Finet et al. 2010). Within this vast group, de novo mechanisms are the most prevalent, based either on the bicentriole or the blepharoplast, as most plants lack CBBs throughout their life cycle except in sperm. The bicentriole appeared in land plants; it is present in most Marchantiophyta and Bryophyta, and in some species of Anthocerotophyta and Lycopodiophyta, but it is absent in the basal Archaeplastida species (Fig. 6; Supplemental Table S1; for review, see Renzaglia and Garbary 2001). Interestingly, a bicentriole is also formed de novo in Labyrinthula spp., a Stramenopila (Fig. 6; Supplemental Table S1). It is possible that the blepharoplast from the Pteridophyta and some gymnosperms derived from the bicentriole. Interestingly, the blepharoplast is mechanistically very similar to the deuterosome, suggesting a scenario of convergent evolution. CBBs are required for species that form motile cilia and somehow depend on a moist environment for fertilization. Gymnosperms (Pinaceae and Gnetales) and all angiosperms (Magnoliophyta) no longer use motile cilia, because fertilization takes place by means of a pollen tube with immotile sperm cells.

It also remains to be understood if, in all the species of Amoebozoa assembling CBBs de novo upon ameboid to flagellate transition (for e.g., Physarum spp.) the mechanisms resemble those found in animals (e.g., in female eggs) or if these have evolved their own specific precursor and uncharacterized pathway. Fungi with CBBs seem to conserve the ancestral canonical pathway of biogenesis, but likely suffered more than one event of centriole loss (Fig. 6).

Throughout the eukaryotic tree, there are several examples of convergent evolution where unrelated groups appear to share similar strategies to assemble CBBs. This suggests that the possibilities for how to make CBBs are somewhat limited, indicating some sort of morphological (perhaps even molecular) constraint inherent to the process.

\section{CONCLUSION}

In this review, we have highlighted that noncanonical modes of CBBs assembly are widespread in the eukaryotic tree. Although some pathways are more lineage-specific, there are several examples of convergent evolution, suggesting that when it comes to making centrioles, the options are limited and mostly governed by numbers.

Most descriptions of noncanonical assembly were done by EM in chemically fixed samples. However, new techniques are now available, such as high-pressure freezing followed by freeze substitution (HPF + FS) and Cryo-EM, which can improve the quality of the data and help to unravel the true representation of each step of these 
processes. Super-resolution microscopy, in particular 3Dstructured illumination microscopy, allows correlating different proteins within the organelles at much better resolution and, potentially, following $\mathrm{CBBs}$ biogenesis live.

Molecular studies on noncanonical centriole biogenesis are scarce and focused on a few species (such as N. gruberi and Drosophila spp.) and biased toward the deuterosome-mediated pathway in vertebrate multiciliated cells. One reason is the absence of tools to study other systems, which can now be overcome with CRISPRCas9 technology and the increasing availability of genomic data. More gene expression data and functional studies should expand our molecular knowledge outside the Opisthokonts, in order to understand what are the universal principles underlying centriole assembly as well as the specific properties inherent to each pathway.

Many of the core centriolar components and some regulators (Polo-like kinases, PCM components, and MT regulators) appear to be conserved across evolution (Hodges et al. 2010; Carvalho-Santos et al. 2010, 2011), suggesting an ancestral molecular cascade, common to most centriole assembly pathways. However, noncanonical centriole biogenesis seems more confined to specific cell types during differentiation (multiciliated cells in vertebrates-deuterosome-mediated pathway) or life-cycle stages ( $N$. gruberi and spermatogenesis in plants-de novo pathways), suggesting that centriole assembly must be under developmental regulation. In the future, it will be important to unravel how the multiple pathways operate in different organisms; how the PCM components, the MT cytoskeleton, and centriolar precursors create a suitable environment that forms a scaffold for centriole assembly. Only then we will fully understand CBBs function and its upstream and downstream molecular machinery.

\section{ACKNOWLEDGMENTS}

The laboratory is funded by the European Research Council Consolidator Grant (CoG683528 CentrioleBirthDeath). C.N. is funded by the Boehringer Ingelheim Fonds and S.G.P. by a Fundação para a Ciência e Tecnologia Grant (PD/BD/114350/2016). We thank Eduardo Marabuto for confirming all the taxonomic information and Maria Francia for clarifying centriole biology in unicellular protozoa and Marc Gouw and collaborators for sharing unpublished information.

\section{REFERENCES}

Al Jord A, Lemaître AI, Delgehyr N, Faucourt M, Spassky N, Meunier A. 2014. Centriole amplification by mother and daughter centrioles differs in multiciliated cells. Nature 516: 104-107.

Anderson RGW, Brenner RM. 1971. The formation of basal bodies (Centrioles) in the Rhesus Monkey oviduct. $J$ Cell Biol 50: 10-34.

Ansley SJ, Badano JL, Blacque OE, Hill J, Hoskins BE, Leitch CC, Kim JC, Ross AJ, Eichers ER, Teslovich TM, et al. 2003. Basal body dysfunction is a likely cause of pleiotropic BardetBiedl syndrome. Nature 425: 628-633.

Arbi M, Pefani DE, Taraviras S, Lygerou Z. 2017. Controlling centriole numbers: Geminin family members as master regu- lators of centriole amplification and multiciliogenesis. Chromosoma doi:10.1007/s00412-017-0652-7.

Azimzadeh J. 2014. Exploring the evolutionary history of centrosomes. Philos Trans R Soc Lond B Biol Sci 369: 20130453.

Azimzadeh J, Wong ML, Downhour DM, Alvarado AS, Marshall WF. 2012. Centrosome loss in the evolution of planarians. Science 335: 461-463.

Baccetyi B, Dallai R. 1978. The spermatozoon of arthropoda. XXX. The multiflagellate spermatozoon in the termite Mastotermes darwiniensis. J Cell Biol 76: 569-576.

Badano JL, Mitsuma N, Beales PL, Katsanis N. 2006. The ciliopathies: An emerging class of human genetic disorders. Annu Rev Genomics Hum Genet 7: 125-148.

Beisson J, Wright M. 2003. Basal body/centriole assembly and continuity. Curr Opin Cell Biol 15: 96-104.

Bettencourt-Dias M, Rodrigues-Martins A, Carpenter L, Riparbelli M, Lehmann L, Gatt MK, Carmo N, Balloux F, Callaini G, Glover DM. 2005. SAK/PLK4 is required for centriole duplication and flagella development. Curr Biol 15: 2199 2207.

Bremer K, Humphries CJ, Mishler BD, Churchill SP. 1987. On cladistic relationships in green plants. Taxon 36: 339-349.

Burki F. 2014. The eukaryotic tree of life from a global phylogenomic perspective. Cold Spring Harb Perspect Biol 6: a016147.

Carvalho-Santos Z, Machado P, Branco P, Tavares-Cadete F, Rodrigues-Martins A, Pereira-Leal JB, Bettencourt-Dias M. 2010. Stepwise evolution of the centriole-assembly pathway. J Cell Sci 123: 1414-1426.

Carvalho-Santos Z, Azimzadeh J, Pereira-Leal JB, BettencourtDias M. 2011. Tracing the origins of centrioles, cilia, and flagella. J Cell Biol 194: 165-175.

Cavalier-Smith T. 2002. The phagotrophic origin of eukaryotes and phylogenetic classification on protozoa. Int J Syst Evol Microbiol 52: 297-354.

Cizmecioglu O, Arnold M, Bahtz R, Settele F, Ehret L, Haselmann-Weiß U, Antony C, Hoffmann I. 2010. Cep152 acts as a scaffold for recruitment of Plk4 and CPAP to the centrosome. $J$ Cell Biol 191: 731-739.

Courtois A, Schuh M, Ellenberg J, Hiiragi T. 2012. The transition from meiotic to mitotic spindle assembly is gradual during early mammalian development. J Cell Biol 198: 357-370.

Dammermann A, Müller-Reichert T, Pelletier L, Habermann B, Desai A, Oegema K. 2004. Centriole assembly requires both centriolar and pericentriolar material proteins. Dev Cell 7: 815-829.

Dingle AD, Fulton C. 1966. Development of the flagellar apparatus of Naegleria. J Cell Biol 31: 43-54.

Dirksen ER. 1961. The presence of centrioles in artificially activated sea urchin eggs. J Cell Biol 11: 244-247.

Dirksen ER. 1971. Centriole morphogenesis in developing ciliated epithelium of the mouse oviduct. J Cell Biol 51: 286-302.

Doonan JH, Lloyd CW, Duckett JG. 1986. Anti-tubulin antibodies locate the blepharoplast during spermatogenesis in the fern Platyzoma microphyllum R.Br.: A correlated immunofluorescence and electron-microscopic study. J Cell Sci 81: 243-265.

Dzhindzhev NS, Yu QD, Weiskopf K, Tzolovsky G, Cunha-Ferreira I, Riparbelli M, Rodrigues-Martins A, Bettencourt-Dias M, Callaini G, Glover DM. 2010. Asterless is a scaffold for the onset of centriole assembly. Nature 467: 714-718.

Ferraguti M, Fascio U, Boi S. 2002. Mass production of basal bodies in paraspermiogenesis of Tubificinae (Annelida, Oligochaeta). Biol Cell 94: 109-115.

Finet C, Fourquin C, Vinauger M, Berne-Dedieu A, Chambrier P, Paindavoine S, Scutt CP. 2010. Parallel structural evolution of auxin response factors in the angiosperms. Plant J63: 952-959.

Fritz-Laylin LK, Fulton C. 2016. Naegleria: A classic model for de novo basal body assembly. Cilia 5: 10 .

Fritz-Laylin LK, Assaf ZJ, Chen S, Cande WZ. 2010. Naegleria gruberi de novo basal body assembly occurs via stepwise incorporation of conserved proteins. Eukaryot Cell 9: 860 865. 
Fritz-Laylin LK, Levy YY, Levitan E, Chen S, Cande WZ, Lai EY, Fulton C. 2016. Rapid centriole assembly in Naegleria reveals conserved roles for both de novo and mentored assembly. Cytoskeleton 73: 109-116.

Fu J, Lipinszki Z, Rangone H, Min M, Mykura C, Chao-Chu J, Schneider S, Dzhindzhev NS, Gottardo M, Riparbelli MG, et al. 2016. Conserved molecular interactions in centriole-tocentrosome conversion. Nat Cell Biol 18: 87-99.

Fulton C, Dingle AD. 1971. Basal bodies, but not centrioles, in naegleria. J Cell Biol 51: 826-835.

Gall JG. 1961. Centriole replication. A study of spermatogenesis in the snail Viviparus. J Biophys Biochem Cytol 10: 163-193.

Ganem NJ, Godinho SA, Pellman D. 2009. A mechanism linking extra centrosomes to chromosomal instability. Nature 460: 278-282.

Garber RC, Aist JR. 1979. The ultrastructure of mitosis in Plasmodiophora brassicae (Plasmodiophorales). J Cell Sci 40: 89110.

Gifford EM, Larson S. 1980. Developmental features of the spermatogenous cell in Ginkgo biloba. Am J Bot 67: 119-124.

Gifford EM, Lin J. 1975. Light microscope and ultrastructural studies of the male gametophyte in Ginkgo biloba: The spermatogenous cell. Am J Bot 62: 974-981.

Godinho SA, Pellman D. 2014. Causes and consequences of centrosome abnormalities in cancer. Philos Trans $R$ Soc $B$ Biol Sci 369: 20130467.

Gopalakrishnan J, Mennella V, Blachon S, Zhai B, Smith AH, Megraw TL, Nicastro D, Gygi SP, Agard DA, Avidor-Reiss T. 2011. Sas-4 provides a scaffold for cytoplasmic complexes and tethers them in a centrosome. Nat Commun 2: 359.

Gueth-Hallonet C, Antony C, Aghion J, Santa-Maria A, LajoieMazenc I, Wright M, Maro B. 1993. $\gamma$-Tubulin is present in acentriolar MTOCs during early mouse development. J Cell Sci 105: 157-166.

Guichard P, Hamel V, Le Guennec M, Banterle N, Iacovache I, Nemcíková V, Flückiger I, Goldie KN, Stahlberg H, Lévy D, et al. 2017. Cell-free reconstitution reveals centriole cartwheel assembly mechanisms. Nat Commun 8: 14813.

Habedanck R, Stierhof YD, Wilkinson CJ, Nigg EA. 2005. The Polo kinase Plk4 functions in centriole duplication. Nat Cell Biol 7: 1140-1146.

Hagiwara H, Ohwada N, Takata K. 2004. Cell biology of normal and abnormal ciliogenesis in the ciliated epithelium. Int Rev Cytol 234: 101-141.

Harrison MK, Adon AM, Saavedra HI. 2011. The G $\mathrm{G}_{1}$ phase Cdks regulate the centrosome cycle and mediate oncogene-dependent centrosome amplification. Cell Div 6: 2 .

Healy JM, Jamieson BGM. 1981. An ultrastructural examination of developing and mature paraspermatozoa in Pyrazus ebeninus (Mollusca, Gastropoda, Potamididae). Zoomorphology 98: $101-119$.

Heath IB. 1974a. Centrioles and mitosis in some oömycetes. Mycologia 66: 354-359.

Heath IB. 1974b. Mitosis in the fungus Thraustotheca clavata. $J$ Cell Biol 60: 204-220.

Heath IB, Greenwood AD. 1970. Centriole replication and nuclear division in Saprolegnia. J Gen Microbiol 62: 139-148.

Hepler PK. 1976. The blepharoplast of Marsilea: its de novo formation and spindle association. J Cell Sci 21: 361-90.

Hodges ME, Scheumann N, Wickstead B, Langdale JA, Gull K. 2010. Reconstructing the evolutionary history of the centriole from protein components. J Cell Sci 123: 1407-1413.

Hoffman JC, Vaughn KC. 1995. Using the developing spermatogenous cells of ceratopteris to unlock the mysteries of the plant cytoskeleton. Int J Plant Sci 156: 346-358.

Hoffman JC, Vaughn KC, Joshi HC. 1994. Structural and immunocytochemical characterization of microtubule organizing centers in pteridophyte spermatogenous cells. Protoplasma 179: 46-60.

Hoh RA, Stowe TR, Turk E, Stearns T. 2012. Transcriptional program of ciliated epithelial cells reveals new cilium and centrosome components and links to human disease. PLoS One 7: e52166.
Judelson HS, Shrivastava J, Manson J. 2012. Decay of genes encoding the oomycete flagellar proteome in the downy mildew Hyaloperonospora arabidopsidis. PLoS One 7: e47624.

Kalnins VI, Porter KR. 1969. Centriole replication during ciliogenesis in the chick tracheal epithelium. Z Zellforsch 100: $1-$ 30 .

Khodjakov A, Rieder CL, Sluder G, Cassels G, Sibon O, Wang C-L. 2002. De novo formation of centrosomes in vertebrate cells arrested during S phase. J Cell Biol 158: 1171-1181.

Kim HK, Kang JG, Yumura S, Walsh CJ, Jin WC, Lee J. 2005. De novo formation of basal bodies in Naegleria gruberi: Regulation by phosphorylation. J Cell Biol 169: 719-724.

Kitagawa D, Vakonakis I, Olieric N, Hilbert M, Keller D, Olieric V, Bortfeld M, Erat MC, Flückiger I, Gönczy P, et al. 2011. Structural basis of the 9-fold symmetry of centrioles. Cell 144: 364-375.

Klink VP, Wolniak SM. 2001. Centrin is necessary for the formation of the motile apparatus in spermatids of Marsilea. Mol Biol Cell 12: 761-776.

Klos Dehring DA, Vladar EK, Werner ME, Mitchell JW, Hwang P, Mitchell BJ. 2013. Deuterosome mediated centriole biogenesis. Dev Cell 27: 103-112.

Kong D, Farmer V, Shukla A, James J, Gruskin R, Kiriyama S, Loncarek J. 2014. Centriole maturation requires regulated Plk1 activity during two consecutive cell cycles. J Cell Biol 206: 855-865.

Kreitner GL, Carothers ZB. 1976. Studies of spermatogenesis in the Hepaticae V. Blepharoplast development in Marchantia polymorpha. Am J Bot 63: 545-557.

Kuriyama R, Borisy GG. 1981. Microtubule-nucleating activity of centrosomes in Chinese hamster ovary cells is independent of the centriole cycle but coupled to the mitotic cycle. J Cell Biol 91: 822-826.

Kuriyama R, Borisy GG, Masui Y. 1986. Microtubule cycles in oocytes of the surf clam, Spisula solidissima: An immunofluorescence study. Dev Biol 114: 151-160.

La Terra S, English CN, Hergert P, McEwen BF, Sluder G, Khodjakov A. 2005. The de novo centriole assembly pathway in HeLa cells: Cell cycle progression and centriole assembly/ maturation. J Cell Biol 168: 713-722.

Lange BMH. 2002. Integration of the centrosome in cell cycle control, stress response and signal transduction pathways. Curr Opin Cell Biol 14: 35-43.

Lee J, Kang S, Choi YS, Kim HK, Yeo CY, Lee Y, Roth J, Lee J. 2015. Identification of a cell cycle-dependent duplicating complex that assembles basal bodies de novo in Naegleria. Protist 166: $1-13$

Levine MS, Bakker B, Boeckx B, Moyett J, Lu J, Vitre B, Spierings DC, Lansdorp PM, Cleveland DW, Lambrechts D, et al. 2017. Centrosome amplification is sufficient to promote spontaneous tumorigenesis in mammals. Dev Cell 40: 313-322.

Loncarek J, Bettencourt-Dias M. 2018. Building the right centriole for each cell type. J Cell Biol. doi: jcb.201704093.

Lopes CAM, Jana SC, Cunha-Ferreira I, Zitouni S, Bento I, Duarte P, Gilberto S, Freixo F, Guerrero A, Francia M, et al. 2015. PLK4 trans-autoactivation controls centriole biogenesis in space. Dev Cell 35: 222-235.

Matsumoto Y, Hayashi K, Nishida E. 1999. Cyclin-dependent kinase $2(\mathrm{Cdk} 2)$ is required for centrosome duplication in mammalian cells. Curr Biol 9: 429-432.

Meraldi P, Lukas J, Fry AM, Bartek J, Nigg EA. 1999. Centrosome duplication in mammalian somatic cells requires E2F and Cdk2-cyclin A. Nat Cell Biol 1: 88-93.

Meunier A, Azimzadeh J. 2016. Multiciliated cells in animals. Cold Spring Harb Perspect Biol 8: a028233.

Miki-Noumura T. 1977. Studies on the de novo formation of centrioles: Aster formation in the activated eggs of sea urchin. J Cell Sci 24: 203-216.

Mizukami I, Gall J. 1966. Centriole replication. II. Sperm formation in the fern, Marsilea, and the cycad, Zamia. J Cell Biol 29: 97-111. 
Mori M, Hazan R, Danielian PS, Mahoney JE, Li H, Lu J, Miller ES, Zhu X, Lees JA, Cardoso W V. 2017. Cytoplasmic E2f4 forms organizing centres for initiation of centriole amplification during multiciliogenesis. Nat Commun 8: 15857.

Moser JW, Kreitner GL. 1970. Centrosome structure in Anthoceros laevis and Marchantia polymorpha. J Cell Biol 44: 454458.

Moser JW, Duckett JG, Carothers ZB. 1977. Ultrastructural studies of spermatogenesis in the anthocerotales. I. The blepharoplast and anterior mitochondrion in Phaeoceros laevis: Early development. Am J Bot 64: 1097-1106.

Nakazawa Y, Hiraki M, Kamiya R, Hirono M. 2007. SAS-6 is a cartwheel protein that establishes the 9-fold symmetry of the centriole. Curr Biol 17: 2169-2174.

Nigg EA, Holland AJ. 2018. Once and only once: Mechanisms of centriole duplication and their deregulation in disease. Nat Rev Mol Cell Biol doi:10.1038/nrm.2017.127.

Norstog K. 1967. Fine structure of the spermatozoid of Zamia with special reference to the flagellar apparatus. Am J Bot 54: 831-840.

Norstog KJ. 1986. The blepharoplast of Zamia pumila L. Bot Cazette 147: 40-46.

Palazzo RE, Vaisberg E, Cole RW, Rieder CL. 1992. Centriole duplication in lysates of Spisula solidissima oocytes. Science 256: 219-221.

Peel N, Stevens NR, Basto R, Raff JW. 2007. Overexpressing centriole-replication proteins in vivo induces centriole overduplication and de novo formation. Curr Biol 17: 834-843.

Perkins FO. 1970. Formation of centriole and centriole-like structures during meiosis and mitosis in Labyrinthula Sp. (Rhizopodea, Labyrinthulida). An electron-microscope study. J Cell Sci 6: 629-653.

Peset I, Vernos I. 2008. The TACC proteins: TACC-ling microtubule dynamics and centrosome function. Trends Cell Biol 18: $379-388$.

Pimenta-Marques A, Bento I, Lopes CAM, Duarte P, Jana SC, Bettencourt-Dias M. 2016. A mechanism for the elimination of the female gamete centrosome in Drosophila melanogaster. Science 353: aaf4866.

Renzaglia KS, Duckett JG. 1987. Spermatogenesis in Blasia pusilla: From young antheridium through mature spermatozoid. Bryologist 90: 419-449.

Renzaglia KS, Garbary DJ. 2001. Motile gametes of land plants: Diversity, development, and evolution. CRC Crit Rev Plant Sci 20: $107-213$.

Renzaglia KS, Maden AR. 2000. Microtubule organizing centers and the origin of centrioles during spermatogenesis in the pteridophyte Phylloglossum. Microsc Res Tech 49: 496-505.

Riparbelli MG, Callaini G. 2003. Drosophila parthenogenesis: A model for de novo centrosome assembly. Dev Biol 260: 298313.

Riparbelli MG, Stouthamer R, Dallai R, Callaini G. 1998. Microtubule organization during the early development of the parthenogenetic egg of the hymenopteran Muscidifurax uniraptor. Dev Biol 195: 89-99.

Riparbelli MG, Callaini G, Mercati D, Hertel H, Dallai R. 2009. Centrioles to basal bodies in the spermiogenesis of Mastotermes darwiniensis (Insecta, Isoptera). Cell Motil Cytoskeleton 66: 248-259.

Robbins RR. 1984. Origin and behavior of bicentriolar centrosomes in the bryophyte Riella americana. Protoplasma 121: 114-119.

Robbins E, Jentzsch G, Micali A. 1968. The centriole cycle in synchronized HeLa cells. J Cell Biol 36: 329-339.

Rodrigues-Martins A, Riparbelli M, Callaini G, Glover DM, Bettencourt-Dias M. 2007. Revisiting the role of the mother centriole in centriole biogenesis. Science 316: 1046-1050.

Schatten G, Simerly C, Schatten H. 1985. Microtubule configurations during fertilization, mitosis, and early development in the mouse and the requirement for egg microtubule-mediated motility during mammalian fertilization. Proc Natl Acad Sci 82: $4152-4156$.
Shimamura M, Brown RC, Lemmon BE, Akashi T, Mizuno K, Nishihara N, Tomizawa K-I, Yoshimoto K, Deguchi H, Hosoya $\mathrm{H}$, et al. 2004. $\gamma$-Tubulin in basal land plants: Characterization, localization, and implication in the evolution of acentriolar microtubule organizing centers. Plant Cell 16: 45-59.

Silkworth WT, Nardi IK, Scholl LM, Cimini D. 2009. Multipolar spindle pole coalescence is a major source of kinetochore misattachment and chromosome mis-segregation in cancer cells. PLoS One 4: e6564.

Sonnen KF, Gabryjonczyk A-M, Anselm E, Stierhof Y-D, Nigg EA. 2013. Human Cep192 and Cep152 cooperate in Plk4 recruitment and centriole duplication. J Cell Sci 126: $3223-$ 3233.

Sorokin SP. 1968. Reconstructions of centriole formation and ciliogenesis in mammalian lungs. $J$ Cell Sci 3: 207-230.

Steinman RM. 1968. An electron microscopic study of ciliogenesis in developing epidermis and trachea in the embryo of Xenopus laevis. Am J Anat 122: 19-55.

Suh MR, Han JW, No YR, Lee J. 2002. Transient concentration of a $\gamma$-tubulin-related protein with a pericentrin-related protein in the formation of basal bodies and flagella during the differentiation of Naegleria gruberi. Cell Motil Cytoskeleton 52: 66-81.

Tamm S, Tamm SL. 1980. Origin and development of free kinetosomes in the flagellates Deltotrichonympha and Koruga. $J$ Cell Sci 42: 189-205.

Tram U, Sullivan W. 2000. Reciprocal inheritance of centrosomes in the parthenogenetic hymenopteran Nasonia vitripennis. Curr Biol 10: 1413-1419.

Uetake Y, Lončarek J, Nordberg JJ, English CN, La Terra S, Khodjakov A, Sluder G. 2007. Cell cycle progression and de novo centriole assembly after centrosomal removal in untransformed human cells. J Cell Biol 176: 173-182.

van Breugel M, Hirono M, Andreeva A, Yanagisawa H, Yamaguchi S, Nakazawa Y, Morgner N, Petrovich M, Ebong I, Robinson C V, et al. 2011. Structures of SAS-6 suggest its organization in centrioles. Science 331: 1196-1199.

Varmark H, Llamazares S, Rebollo E, Lange B, Reina J, Schwarz H, Gonzalez C. 2007. Asterless is a centriolar protein required for centrosome function and embryo development in Drosophila. Curr Biol 17: 1735-1745.

Vaughn KC, Bowling AJ. 2008. Recovery of microtubules on the blepharoplast of Ceratopteris spermatogenous cells after oryzalin treatment. Protoplasma 233: 231-240.

Vaughn KC, Renzaglia KS. 2006. Structural and immunocytochemical characterization of the Ginkgo biloba L. sperm motility apparatus. Protoplasma 227: 165-173.

Vladar EK, Stearns T. 2007. Molecular characterization of centriole assembly in ciliated epithelial cells. J Cell Biol 178: $31-42$.

Woodland HR, Fry AM. 2008. Pix proteins and the evolution of centrioles. PLoS One 3: e3778.

Woodruff JB, Ferreira Gomes B, Widlund PO, Mahamid J, Honigmann A, Hyman AA. 2017. The centrosome is a selective condensate that nucleates microtubules by concentrating tubulin. Cell 169: 1066-1077.

Worden AZ, Follows MJ, Giovannoni SJ, Wilken S, Zimmerman AE, Keeling PJ. 2015. Rethinking the marine carbon cycle: Factoring in the multifarious lifestyles of microbes. Science 347.

Yubuki N, Leander BS. 2013. Evolution of microtubule organizing centers across the tree of eukaryotes. Plant J 75: 230-244.

Zhao H, Zhu L, Zhu Y, Cao J, Li S, Huang Q, Xu T, Huang X, Yan X, Zhu X. 2013. The cep63 paralogue deup1 enables massive de novo centriole biogenesis for vertebrate multiciliogenesis. Nat Cell Biol 15: 1434-1444.

Zitouni S, Francia ME, Leal F, Gouveia SM, Nabais C, Duarte P, Gilberto S, Brito D, Moyer T, Ohta M, et al. 2016. CDK1 prevents unscheduled PLK4-STIL complex assembly in centriole biogenesis. Curr Biol 26: 1127-1137. 


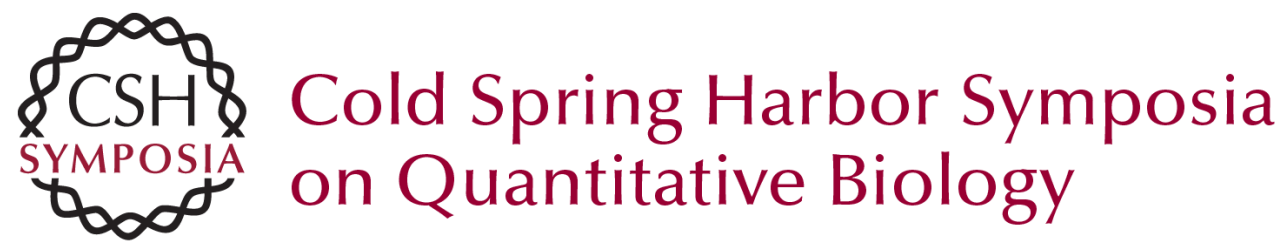

\section{Noncanonical Biogenesis of Centrioles and Basal Bodies}

Catarina Nabais, Sónia Gomes Pereira and Mónica Bettencourt-Dias

Cold Spring Harb Symp Quant Biol 2017 82: 123-135 originally published online April 23, 2018 Access the most recent version at doi:10.1101/sqb.2017.82.034694

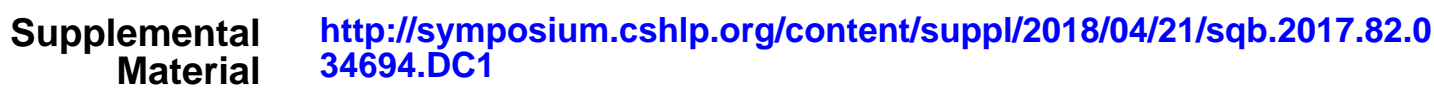

References This article cites 113 articles, 43 of which can be accessed free at: http://symposium.cshlp.org/content/82/123.full.html\#ref-list-1

Creative This article is distributed under the terms of the

Commons http://creativecommons.org/licenses/by-nc/4.0/, which permits reuse and License redistribution, except for commercial purposes, provided that the original author and source are credited.

Email Alerting Receive free email alerts when new articles cite this article - sign up in Service the box at the top right corner of the article or click here. 